\title{
SOBRE LA CONFIGURACIÓN FORMAL DE GALICISMOS LÉXICOS COMO PALABRAS IDIOMÁTICAS EN ESTRUCTURAS LOCUCIONALES EN ESPAÑOL
}

\section{MORPHOLOGY OF LOANWORDS FROM FRENCH AS IDIOMATIC WORDS IN SPANISH IDIOMS}

\author{
Manuel José Aguilar Ruiz \\ Universidad de Valencia \\ Manuel.J.Aguilar@uv.es
}

\begin{abstract}
RESUMEN
El objetivo del presente artículo es ofrecer un análisis de la configuración formal de un tipo muy concreto de palabras idiomáticas: nueve préstamos léxicos procedentes del francés que sobreviven insertos en locuciones en español. Para ello, delimitaremos los conceptos de palabra idiomática, préstamo léxico y galicismo, y expondremos un procedimiento metodológico lexicográfico para recopilar este tipo de voces en diccionarios generales actuales como el DLE y el DEA. A continuación, se procederá al análisis lexicogenético y morfológico de las nueve voces idiomáticas, para intentar extraer una valoración global sobre su configuración.
\end{abstract}

Palabras clave: fraseología, locución, español, galicismo, palabra idiomática.

\begin{abstract}
The aim of this paper is to offer an analysis of the morphology of a very specific kind of idiomatic words: nine loanwords from French that survive inserted in Spanish idioms. We will first define the concepts idiomatic word, loanword, and loanword from French, and then we expose a lexicographical method to compile this kind of words in general dictionaries such as DLE o DEA. Next, we will proceed to an etymological and morphological analysis of the nine idiomatic words, so that try to extract a global assessment of their configuration.
\end{abstract}

Keywords: phraseology; idiom; Spanish; loanword from French; idiomatic word. 


\section{EL CONCEPTO DE PALABRA IDIOMÁTICA O PALABRA DIACRÍTICA. LOS PRÉSTAMOS FRASEOLÓ GICOS COMO PALABRAS IDIOMÁTICAS}

En los últimos años, las investigaciones y publicaciones relativas a la fraseología en español han conocido un considerable impulso. En estos estudios, se han venido conociendo bajo las denominaciones de palabras idiomáticas o diacríticas aquellas piezas léxicas que carecen de significado y limitan su posibilidad de aparición dentro de un fraseologismo ${ }^{1}$. Serían voces como rajatabla, vilo o tutiplén, presentes en las locuciones adverbiales a rajatabla ${ }^{2}$, en vilo ${ }^{3}$ y a tutiplén ${ }^{4}$, respectivamente, caracterizadas, pues, por: 1) su falta de autonomía semántica, ya que son palabras que carecen de un significado específico, hasta el punto de que los diccionarios difícilmente pueden ofrecer una definición concreta para ellas, y 2) su falta de autonomía sintáctica, debida a su incapacidad general de aparición en la sintaxis libre, pues parecen tener reducida su posibilidad de actualización exclusivamente al "discurso repetido" (Boer, 1954; Coseriu, 1986), esto es, a las unidades fraseológicas que las contienen. Esta concepción basada en la total asemanticidad y la imposibilidad de aparición en el discurso libre se inserta en una perspectiva muy estricta del concepto de palabra diacrítica o idiomática, ya que desde concepciones más amplias puede ser suficiente con la susceptible pérdida de disponibilidad léxica de una voz para que esta pueda concebirse como idiomática (Ruiz Gurillo, 1997, pp. 75-76, 1998, pp. 19-22 y 2001, pp. 52-53; Martínez López, 1997-1998, pp. 864-865), matizando la restricción de significado (García-Page Sánchez, 2008, p. 353).

Respecto a su clasificación, los distintos fraseólogos han solido dividir las palabras idiomáticas dependiendo del origen de estas 5 . Algunas suponen piezas léxicas supervivientes de épocas pretéritas del castellano que no llegaron a consolidarse de

\footnotetext{
1 Cfr. Zuluaga Ospina (1980, pp. 102-103); García-Page Sánchez (1990, 1991, 2008, pp. 352-362); Corpas Pastor (1996, pp. 115-116); Ruiz Gurillo (1997, pp. 75-76, 1998, pp. 19-21, 2001, pp. 21-25, 5253); Martínez López (1997-1998, pp. 859-860); Zurita (2008) y Aguilar Ruiz (2010, 2014, pp. 267-268), entre otros.

2 'loc. adv. De manera estricta, precisa o rigurosa' (DLE, s. v. rajatabla).

3 '1. loc. adv. Sin el apoyo físico necesario o sin estabilidad. 2. loc. adv. Con indecisión, inquietud y zozobra' (DLE, s. v. vilo).

4 'loc. adv. En abundancia, a porrillo' (DLE, s. v. tutiplén).

${ }^{5}$ Cfr., como visión sinóptica, García-Page Sánchez (2008: 355 y sigs.).
} 
manera definitiva en el sistema y que permanecen, en la sincronía actual, insertas dentro de una unidad fraseológica, como ende o volandas en las locuciones adverbiales por ende ${ }^{6}$ y en volandas ${ }^{7}$; son los denominados fósiles fraseológicos (Aguilar Ruiz, 2010, 2011). Otras, los neologismos fraseológicos (Aguilar Ruiz, 2010, 2012), se han originado a través de los mecanismos internos de los que dispone la lengua para multiplicar su léxico (los procedimientos de derivación, composición, parasíntesis, etc.; cfr. Moreno Cabrera, 2004, p. 145; Penny, 2014, p. 234), como antemano, horcajadas o rajatabla en las locuciones adverbiales de antemano $^{8}$, a horcajadas ${ }^{9}$ y a rajatabla $^{10}$. La tercera gran fuente de formación de palabras idiomáticas que los estudiosos suelen reconocer consiste en la importación de piezas léxicas foráneas cuya única posibilidad de actualización ocurre dentro de un fraseologismo, como detall y granel, provenientes de la lengua catalana e integrantes de las locuciones al detall ${ }^{11}$ y a granel ${ }^{2}$ (Aguilar Ruiz, en prensa); a estas las hemos venido conociendo con el nombre de préstamos fraseológicos (Aguilar Ruiz, 2010), y pueden clasificarse según la lengua histórica, distinta del español, de la que proceden (Ruiz Gurillo, 1997, p. 75), de manera que podemos hablar, por ejemplo, de latinismos, arabismos, catalanismos o italianismos fraseológicos.

Nuestra propuesta clasificatoria pretende resumir estas tres fuentes generales de formación y adquisición de voces idiomáticas en el esquema tripartito con el que en la tradición hispánica Seco Reymundo (1991), Álvarez de Miranda (2009, 2013) y Battaner Arias y López Ferrero (2019), entre otros autores, categorizan el léxico general respecto a su origen, como son el "léxico heredado" o "voces patrimoniales" (nuestros "fósiles fraseológicos"), el "léxico adquirido" o "voces prestadas" (nuestros "préstamos fraseológicos") y, por último, el "léxico multiplicado" o "creaciones

\footnotetext{
6 'loc. adv. por tanto' (DLE, s. v. ende).

7 '1. loc. adv. Por el aire o levantado del suelo y como que va volando. 2. loc. adv. coloq. Rápidamente, en un instante' (DLE, s. v. volandas).

8 'loc. adv. Con anticipación, anteriormente' (DLE, s. v. antemano).

9 'loc. adv. Dicho de montar, cabalgar o sentarse: Con una pierna a cada lado de la caballería, persona o cosa sobre la que se está' (DLE, s. v. horcajadas).

10 '1. loc. adv. De manera estricta, precisa o rigurosa. 2. loc. adv. p. us. A toda costa y resueltamente, pese a los riesgos o dificultades' (DLE, s. v. rajatabla).

11 'loc. adv. Al por menor. U. t. c. loc. adj.' (DLE, s. v. detall).

12 '1. loc. adj. Dicho de cosas menudas, como trigo, centeno, etc.: Sin orden, número ni medida. U. t. c. loc. adv. 2. loc. adj. Dicho de un género: Sin envase, sin empaquetar. U. t. c. loc. adv.' (DLE, s. v. granel).
} 
internas de la lengua" (nuestros "neologismos fraseológicos"). Otras voces con difícil atribución de un significado preciso (Corpas Pastor, 1996: 116) contemplables como idiomáticas, como nombres propios del tipo Carracuca ${ }^{13}$, Maricastaña ${ }^{14}$, Picio ${ }^{15}$ o $V_{\text {Villadiego }}{ }^{16}$, podrían insertarse, según su proceso de lexicogénesis, en uno de estos tres grupos generales, al igual que las originadas mediante deformaciones fónicas del tipo pispás $^{17}$, lirondo ${ }^{18}$ o tuntún $^{19}$ o seudosufijos latinizantes o falsos cortes como extranjiis ${ }^{20}$, bóbilis $^{21}$ o busilis ${ }^{22}$ (cfr. García-Page Sánchez, 2008, pp. 361-362).

\section{OBJETIVOS DEL PRESENTE TRABAJO. PROCEDIMIENTOS METODOLÓGICOS PARA LA RECOPILACIÓN DE PALABRAS IDIOMÁTICAS}

El objetivo de este trabajo es llevar a cabo un análisis de lo que podríamos denominar galicismos fraseológicos, esto es, de aquellas palabras idiomáticas que, en calidad de préstamos del francés, han quedado insertas en unidades fraseológicas españolas. Nos limitamos, desde una perspectiva estrecha de la concepción de la fraseología (GarcíaPage Sánchez, 2008; Penadés Martínez, 2012, pp. 63-65), al ámbito fraseológico de las locuciones, dejando a un lado, pues, fraseologismos que puedan catalogarse como colocaciones o paremias (cfr. Corpas Pastor, 1996).

Una forma de inventariar las palabras idiomáticas en español, concebidas desde una perspectiva estrecha y ya llevada a cabo en trabajos anteriores (Aguilar Ruiz, 2019, 2020 y en prensa), consistiría en ayudarnos del especial tratamiento lexicográfico que estas voces anómalas reciben por parte de los diccionarios, sirviéndonos de las numerosas

\footnotetext{
13 Presente en la construcción fija estar más perdido que Carracuca [alguien] ('loc. verb. U. para ponderar la situación angustiosa o comprometida de alguien', DLE, s. v. Carracuca).

${ }^{14}$ En (en tiempos) de Maricastaña ('loc. adv. coloq. [Tiempo] muy remoto. Con intención ponderativa', $D E A$, s. v. Maricastaña).

${ }^{15}$ En más feo que Picio ('loc. adj. coloq. Dicho de una persona: Excesivamente fea', DLE, s. v. Picio).

${ }^{16} \mathrm{En}$ \{coger/tomar\} las de Villadiego [alguien] ('loc. verb. coloq. Ausentarse impensadamente, de ordinario por huir de un riesgo o compromiso', DLE, s. v. Villadiego).

17 Presente en la locución adverbial en un \{pispás/pis pás/plis-plas/plis plas\} ('loc. adv. En un santiamén', DLE, s. v. pispás).

${ }^{18}$ En mondo y lirondo ('loc. adj. coloq. Limpio, sin añadidura alguna', DLE, s. v. lirondo).

${ }^{19}$ En al (buen) \{tuntún/tun-tun/tun tun\} ('loc. adv. coloq. Sin cálculo ni reflexión o sin conocimiento del asunto', DLE, s. v. tuntún).

${ }^{20}$ En de extranjis ('loc. adv. De tapadillo, subrepticiamente', DLE, s. v. extranjis).

${ }^{21}$ En de bóbilis, bóbilis ('loc. adv. coloq. 1. De balde. 2. Sin trabajo', DLE, s. v. bóbilis).

${ }^{22}$ En dar en el busilis [alguien] ('loc. verb. coloq. Dar en el hito', DLE, s. v. busilis).
} 
contribuciones que los estudios lexicográficos ofrecen para las investigaciones fraseológicas (Ruiz Gurillo, 1997, p. 40, 2001, 62-64). De esta manera, siguiendo una técnica lexicográfica planteada por Haensch (1982, p. 456), las palabras idiomáticas suelen lematizarse en un repertorio léxico como entradas independientes en el aparato macroestructural y, seguidamente (ante la incapacidad de definición del lema), se remite de forma inmediata a la(s) locución(es) de la que forman parte (Haensch, 1982, p. 456; Wotjak, 1998, p. 352; Ruiz Gurillo, 2000, p. 264; Castillo Carballo, 2003, p. 93), siendo sustituida la voz idiomática lematizada por una virgulilla $(\sim) .{ }^{23}$ Como ejemplo de esta técnica lexicográfica podría tomarse el tratamiento del lema tutiplén por parte del diccionario académico (DLE, 2014), en la figura 1:

tutiplén. (Forma viciosa del lat. totus 'todo' y plenus

'lleno'). a . loc. adv. coloq. En abundancia, a porrillo.

Figura 1. Tratamiento lexicográfico del DLE de la palabra idiomática tutiplén

Así pues, en el presente artículo recogemos aquellas voces idiomáticas lematizadas con la técnica lexicográfica de Haensch (1982, p. 456) en dos diccionarios generales de

${ }^{23}$ Como se ha comentado antes, esta perspectiva obedece a una concepción estrecha del concepto de palabra idiomática. Algunos autores pueden sentir como tales voces (si bien no galicismos) del tipo ambages, polvorosa o soslayo, integrantes de las locuciones sin ambages ('loc. adv. Sin rodeos o circunloquios', DFDEA, s. v. ambages), poner pies en polvorosa [alguien] ('loc. verb. coloq. Huir', DEA; s. v. pie) y $\{$ al/ de $\}$ soslayo ('loc. adv. Oblicuamente. De costado y perfilando bien el cuerpo para pasar por alguna estrechura', DLE, s. v. soslayo). Sin embargo, para estas voces que difícilmente podrían actualizarse fuera del discurso repetido (Ruiz Gurillo, 2001, p. 52), el diccionario académico ofrece una definición específica como piezas léxicas independientes (en concreto, para ambages, 'm. pl. Rodeos de palabras o circunloquios'; para polvorosa, 'adj. Que tiene mucho polvo', y para soslayo, 'adj. Soslayado, oblicuo'). La recopilación de este tipo de palabras, si se conciben como idiomáticas desde una perspectiva amplia, conllevaría emplear procedimientos metodológicos distintos a los empleados aquí (por ejemplo, una recopilación de todos los lemas que el diccionario académico ofrezca como préstamos del francés e integrantes de una locución, con la posterior documentación exhaustiva en corpus para comprobar su posibilidad de aparición en la sintaxis libre en la sincronía actual, con lo que verificar si su aparición se reduce efectivamente a los marcos locucionales de los que forman parte). Entre las limitaciones observables en nuestro procedimiento metodológico, cabría la ausencia de voces —en este caso, no galicismos- que diversos autores (García-Page Sánchez, 2008, pp. 352-362; Martí Contreras, 2003, 2005; Zurita, 2008, etc.) evidencian como idiomáticas, pero que la tradición lexicográfica académica o el $D E A$ no han llegado a lematizar, del tipo boquiqui, Guatepeor y miranda en los fraseologismos ser un boquiqui [alguien] ('Hablar en demasía, por lo general de lo que no se debe', DDFH, s. v. ser un bocazas), salir de Guatemala $\{y /$ para $\}$ meterse en Guatepeor [alguien] ('inf. Frase con que se describe o comenta el hecho de acabar una situación mala o desagradable y caer en otra que lo es todavía más', DUE, s. v. Guatepeor), estar de miranda [alguien] ('Estar observando algo, sin hacer nada', DDFH), o los compuestos lexicalizados bañalamo, rajacinche, revientacalderas o trompatalega en las locuciones a bañalomo, a rajacinche, a revientacalderas y a trompatalega (apud García-Page Sánchez, 1990, 1991 y 2008). 
español de distinta planta -el diccionario académico (DLE, 2014), por un lado, y el Diccionario del español actual $(D E A)$ de Seco Reymundo, Andrés Puente y Ramos González (2011), por otro- a las que diccionarios con información etimológica como el propio DLE o el Diccionario crítico etimológico castellano e hispánico (DCECH) de Coromines i Vigneaux y Pascual Rodríguez (1980-1992) atribuyen un origen a partir de la lengua francesa. En ocasiones puntuales esta atribución se ha contrastado con la información recopilada en diccionarios históricos y etimológicos de la lengua francesa, como el Dictionnaire historique de la langue française (LRDHLF) de Rey (2000) o el Dictionnaire etymologique du français (DEF) de Picoche (1991), el Le Petit Robert-Langue française (LPRLF) de Rey, Rey-Debove y Robert (2004) y también mediante la consulta de un diccionario especializado (fraseológico) como el Diccionario temático de locuciones francesas con su correspondencia española (DTLCCE) de Sevilla Muñoz y Cantera Ortiz de Urbina (2004).

Hemos excluido, pues, lemas de origen francés para los que los diccionarios son capaces de ofrecer una definición concreta como piezas léxicas, como el sustantivo bies (presente en la locución adverbial al bies ${ }^{24}$ ), el cual, desde una perspectiva amplia del fenómeno léxico-fraseológico que aquí nos ocupa, se ha solido citar como palabra idiomática (Corpas Pastor, 1996, p. 116; Ruiz Gurillo, 2001, p. 52; Aguilar Ruiz, 2010, p. 373 ; etc.), a pesar de que el diccionario académico presenta un significado específico como pieza léxica ${ }^{25}$. También se han desechado lemas que han desaparecido del aparato macroestuctural de los diccionarios empleados, a pesar de que se lematizaran como voces idiomáticas en versiones anteriores, como force, que suponía un préstamo del francés en el fraseologismo tour de force ${ }^{26}$ según la edición anterior del diccionario académico (DRAE22, s. v. force), pero que ha desaparecido de la macroestructura de la nueva edición del DLE (en el que se lematiza como una locución enteramente importada ${ }^{27}$ ).

24 'loc. adv. Al sesgo, en diagonal' (DLE, s. v. bies).

25 '(Del fr. biais, 'sesgo'). m. Trozo de tela cortado al sesgo respecto al hilo, que se aplica a los bordes de algunas prendas, (DLE, s. v. bies).

26 'm. Esfuerzo grande, físico o anímico' (DRAE22, s. v. tour).

27 ‘(Loc. fr.). m. Esfuerzo grande, físico o anímico' (DLE, s. v. tour de force). Así, esta construcción habría de considerarse como una locución de origen foráneo enteramente importada y sin presencia de voces 
No se ha contado, además, con palabras idiomáticas que tienen una etimología francesa dudosa o insegura, como cupitel, garete, remanguillé y ultranza (presentes en las locuciones tirar de cupitel [alguien $]^{28}$, al garete ${ }^{29}$, irse al garete $[\text { algo }]^{30}$, a la remanguille ${ }^{31}$ y a ultran $\left.a^{32}\right)$, de etimología problemática, ya que suponen voces con étimos inseguros y oscuros para los que el DLE y el DCECH presentan discrepancias, por lo que se optaría por considerarlas como voces idiomáticas "inclasificadas" o "de etimología imprecisa". Por último, tampoco forma parte de los galicismos fraseológicos aquí estudiados la voz idiomática chápiro, ya que, según la información etimológica del DLE (s. v. chápiro) y del DCECH (s. v. capa), su proceso lexicogenético ha tenido lugar mediante un proceso interno de sufijación, partiendo de la base de una voz tomada del francés, de manera que no sería propiamente un galicismo, sino una palabra diacrítica originada mediante mecanismos morfológicos del español (en concreto, por sufijación).

\section{CARACTERIZACIÓN GENERAL DE LOS GALICISMOS COMO PRÉSTAMOS LÉXICOS}

Los galicismos (cfr. Pottier, 1967, p. 126; Lapesa Melgar, 1981, p. 168; Penny, 2014, p. 299) son los préstamos léxicos procedentes de la lengua francesa. Suele apuntarse (Posner, 1998, p. 233; Medina López, 1997, p. 15) que la afluencia de galicismos en español ha sido una constante a lo largo de la historia, debido al continuo contacto de ambas lenguas. De hecho, autores como Pottier (1967, p. 128) y Colón Doménech (2002, p. 36) observan que el grado de contacto entre catalán y español ha sido tal, que

españolas en su fijación formal, del mismo tipo que las locuciones latinas ex cathedra ('loc. adv. despect. En tono magistral y decisivo', DLE, s. v. ex cathedra), in albis ('loc. adv. 1. Sin lograr lo que se esperaba. 2. En blanco (\| sin comprender lo que se oye o lee', DLE, s. v. in albis), ipso facto ('loc. adv. Por el mismo hecho, inmediatamente, en el acto', DLE, s. $v$. ipso facto) o post mortem ('loc. adj. Después de la muerte. U. t. c. loc. adv.', DLE, s. v. post mortem) (vid. Aguilar Ruiz, 2014: 273-276), y no como una pieza léxica prestada insertada en una locución en español (esto es, una palabra diacrítica).

28 'loc. verb. En el juego de bochas, arrojar por alto la bola para que, al caer, dé a otra contraria y la aparte' (DLE, s. v. cupite).

29 'loc. adv. A la deriva' (DLE, s. v. garete).

30 'loc. verb. coloq. Fracasar o malograrse. Su fortuna se fue al garete’ (DLE, s. v. garete).

31 'loc. adv. y adj. coloq. 1. De forma desordenada. 2. De manera descuidada o imprecisa. 3. De forma inadecuada' (DLE, s. v. remanguillè).

32 'loc. adv. 1. A muerte. 2. A todo trance, resueltamente' (DLE, s. v. ultranza). 
el francés puede considerarse como la lengua románica que más voces ha prestado al español, seguida del italiano (Álvarez de Miranda, 2013, p. 1052-1054). Por su parte, los préstamos de los demás romances parecen haber sido más limitados (cfr. Lapesa Melgar, 1981, p. 456).

Sin embargo, la afluencia de préstamos léxicos procedentes de la francesa no ha sido siempre constante, sino que es posible establecer determinadas periodizaciones. Un estudio que se ha venido considerado muy relevante para la investigación sobre la adquisición de galicismos en España y su periodización es Pottier (1967) ${ }^{33}$. Con él y otros estudiosos podemos resumir que el influjo del francés sobre el español tuvo cierta relevancia entre los siglos XI-XIII (Cano Aguilar, 2015, p. 238), sobre todo por la llegada de cluniacenses y cistercenses (Colón Doménech, 2002, p. 36), aunque, como observan diversos estudiosos (Lapesa Melgar, 1981, p. 199; Pico Graña y Corbella Díaz, 1987-1988, p. 368; Clavería Nadal, 2013, p. 481; Penny, 2014, p. 300), en dicho periodo puede resultar difícil diferenciar frecuentemente este tipo de préstamo léxico de los occitanismos (es decir, de los préstamos léxicos procedentes de la lengua occitana; cfr. Clavería Nadal, 2013, p. 481). La incorporación de galicismos decayó a partir del siglo XIV (Colón Doménech, 2002, p. 36), para elevar al máximo de nuevo su influencia en el XVIII (Pico Graña y Corbella Díaz, 1987-1988, p. 387), hasta el punto de que apunta Posner (1998, p. 232) que los siglos XVIII y XIX supusieron el momento álgido de los galicismos en todas las lenguas romances. La influencia del francés retrocedió otra vez en el siglo XX (Colón Doménech, 2002, p. 37; Cano Aguilar, 2015, p. 286) para acabar cediendo al inglés su condición de primera lengua proporcionadora de préstamos en español (Lorenzo Criado, 1996, p. 23). De este modo, como se puede resumir a partir de Penny (2014, pp. 300-302), la afluencia masiva de galicismos ha coincidido, de manera general, con dos momentos históricos puntuales de la importancia cultural de Francia, como son la Baja Edad Media y el periodo comprendido entre los siglos XVIII y XIX, por lo que la adopción de galicismos en español ha venido motivada fundamentalmente, como suele ser usual,

33 Aunque dicho trabajo pudiera precisar, en la actualidad, cierta revisión, como observa Álvarez de Miranda (2013, p. 1053). 
no solo por la intensidad del fenómeno de contacto entre ambas lenguas, sino también por el factor de prestigio de la lengua exportadora (Lapesa Melgar, 1981, p. 200; Campbell, 1999, pp. 59-60; Cano Aguilar, 2015, p. 275).

Respecto a los campos léxicos que se han enriquecido en castellano a través de los préstamos léxicos procedentes del francés, suelen reseñarse el mundo de la milicia y el naval, el literario, el religioso, el ámbito privado del hogar (mobiliario, vestimenta, moda), el de los alimentos y las cuestiones culinarias, las finanzas, el comercio, etc. (cfr. Lapesa Melgar, 1981, p. 410; Clavería Nadal, 2013, p. 481; Penny, 2014, p. 300-302; Cano Aguilar, 2015, p. 286-287).

\section{CORPUS DE TRABAJO: GALICISMOS COMO PRÉSTAMOS FRASEOLÓGICOS EN LOCUCIONES ESPAÑOLAS}

Como puede verse en la tabla 1 , como resultado de nuestro vaciado del DLE y del $D E A$ contamos con nueve voces idiomáticas procedentes de la lengua francesa. Conforman un total de once locuciones distintas, pues dos de estas palabras (rondón y vis) integran dos locuciones cada una (la adverbial de rondón y la verbal entrar de rondón [alguien], por un lado, y la locución adverbial y sustantiva vis a vis, por otro). Solo una de estas voces (garsón y sus variantes garçon y garçonne) se encuentra lematizada exclusivamente en el $D E A$; las restantes provienen de su lematización en el diccionario académico.

\begin{tabular}{|c|c|c|}
\hline PALABRA IDIOMÁTICA & ETIMOLOGÍA & LOCUCIÓN, TIPO Y SIGNIFICADO \\
\hline \multirow{3}{*}{ bote } & \multirow{3}{*}{$\begin{array}{l}\text { Del francés antiguo bout, } \\
\text { imitación de la locución de } \\
\text { bout en bout, 'de un } \\
\text { extremo al otro' } \\
(D C E C H, \text { s. v. bote IV; } \\
\text { LPRLF, s. v. bout; } \\
\text { DTLCCE, s. v. bote) }\end{array}$} & de bote $\{a / e n\}$ bote \\
\hline & & loc. adj. [coloq.] \\
\hline & & $\begin{array}{l}\text { 'Dicho de un sitio o de un local: Lleno de } \\
\text { gente completamente' (DLE, s. v. botes) }\end{array}$ \\
\hline \multirow{3}{*}{ estricote } & \multirow{3}{*}{$\begin{array}{l}\text { Quizá de un francés } \\
\text { antiguo *estricot (hoy tricot), } \\
\text { 'garrote' (DCECH, s. } v \text {. al } \\
\text { estricote). La base tricot } \\
\text { deriva del verbo tricoter } \\
\text { (LRDHLF, s. v. tricot) }\end{array}$} & al estricote \\
\hline & & loc. adv. \\
\hline & & $\begin{array}{l}\text { ‘Al retortero o a mal traer' (DLE, s. } v \text {. } \\
\text { estricote) }\end{array}$ \\
\hline \multirow{2}{*}{ garsón/garçon/garçonne } & \multirow{2}{*}{$\begin{array}{l}\text { Tomado del fr. garçon } \\
\text { 'muchacho' (DCECH, s. v. } \\
\text { garæón })\end{array}$} & a lo $\{$ garsón/garçon/garçonne $\}$ \\
\hline & & loc. policat. (adj. y adv.) \\
\hline
\end{tabular}




\begin{tabular}{|c|c|c|}
\hline & $\begin{array}{l}\text { Imitada de à la garçonne } \\
\text { 'Avec des allures de } \\
\text { garçon' (LPRLF, s. } v \text {. } \\
\text { garçon) }\end{array}$ & $\begin{array}{l}\text { 'Al estilo de los muchachos. Referido } \\
\text { especialmente al corte de pelo en las } \\
\text { mujeres' (DEA, s. v. garçon) }\end{array}$ \\
\hline \multirow{3}{*}{ gogó } & \multirow{3}{*}{$\begin{array}{l}\text { Del francés à gogo (DLE, } \\
\text { s. v. gogó), voz que supone } \\
\text { también una palabra } \\
\text { idiomática en lengua } \\
\text { francesa ( } L P R L F, \text { s. v. à } \\
\text { gogo), relacionada con la } \\
\text { antigua gogue } \\
\text { ('Rejouissance, liesse', } \\
\text { DEF y LRDHLF, s. v. } \\
\text { gogue) }\end{array}$} & a gogó \\
\hline & & loc. adv. [coloq.] \\
\hline & & 'Sin límite' (DLE, s. v. gogó) \\
\hline \multirow[b]{3}{*}{ gratín } & \multirow{3}{*}{$\begin{array}{l}\text { Del francés au gratin } \\
(D L E, s . v \cdot \text { gratín })\end{array}$} & al gratin \\
\hline & & loc. adj. \\
\hline & & $\begin{array}{l}\text { 'Dicho de un alimento: Metido en el } \\
\text { horno después de cocinado, para que se } \\
\text { gratine' (DLE, s. v. gratin) }\end{array}$ \\
\hline \multirow{3}{*}{ pitimini } & \multirow{2}{*}{$\begin{array}{l}\text { Del francés petit, } \\
\text { 'pequeño', y menu, } \\
\text { 'menudo' (DLE, s. } v \text {. } \\
\text { pitimini) }\end{array}$} & de pitiminí \\
\hline & & loc. adj. \\
\hline & $\begin{array}{l}\text { Del fr. petit y menu, } \\
\text { 'menudo' (DCECH, s. v. } \\
\text { pepitoria) }\end{array}$ & 'De poca importancia' (DLE, s. v. pitimini \\
\hline \multirow{6}{*}{ rondón/rendón } & \multirow{6}{*}{$\begin{array}{l}\text { Del francés antiguo randon } \\
(D L E, s . v \cdot \text { rondón) } \\
\text { Tomado del fr. ant. de } \\
\text { randon, 'corriendo, } \\
\text { rápidamente' (DCECH, s. } \\
v . \text { de rondón) }\end{array}$} & de $\{$ rondón/rendón $\}$ \\
\hline & & loc. adv. \\
\hline & & $\begin{array}{l}\text { 'Intrépidamente y sin reparo' (DLE, s. } v \text {. } \\
\text { rondón) }\end{array}$ \\
\hline & & entrar de rondón [alguien] \\
\hline & & loc. verb. [coloq.] \\
\hline & & $\begin{array}{l}\text { 'Entrar de repente y con familiaridad, sin } \\
\text { llamar a la puerta, dar aviso, tener licencia } \\
\text { ni esperar ser llamado' (DLE, s. v. rondón) }\end{array}$ \\
\hline \multirow{4}{*}{ virulé } & \multirow{3}{*}{$\begin{array}{l}\text { Del francés bas roulé, que } \\
\text { se aplicó originariamente } \\
\text { a la manera de llevar las } \\
\text { medias (DLE, s. v. virulé) }\end{array}$} & a la virulé \\
\hline & & loc. adj. \\
\hline & & '1. Desordenado, de mala traza 2. \\
\hline & $\begin{array}{l}\text { Parece ser alteración del } \\
\text { fr. bas roulé, 'media } \\
\text { arrollada' (DCECH, s. } v \text {. } \\
\text { bajo) }\end{array}$ & $\begin{array}{l}\text { Estropeado, torcido o en mal estado } 3 \text {. } \\
\text { [coloq.] Chiflado. 4. [desus.] Dicho de } \\
\text { una media: Arrollada en su parte superior' } \\
\text { (DLE, s. v. virulé) }\end{array}$ \\
\hline \multirow{5}{*}{ vis } & \multirow{2}{*}{$\begin{array}{l}\text { Del francés vis-à-vis (DLE, } \\
\text { s. v. vis2) }\end{array}$} & vis a vis \\
\hline & & loc. adv. \\
\hline & \multirow{3}{*}{$\begin{array}{l}\text { Tomada de la loc. adv. y } \\
\text { adj. francesa vis-à-vis ('Face } \\
\text { à face; Position de deux } \\
\text { personnes, deux choses } \\
\text { qui se font face, tête-à- } \\
\text { tête', LPRLF, s. v. vis), } \\
\text { formada a partir de }\end{array}$} & $\begin{array}{l}\text { 'Cara a cara' (DLE, s. v. vis) } \\
\text { vis a vis }\end{array}$ \\
\hline & & loc. sust. \\
\hline & & $\begin{array}{l}\text { 'En las prisiones, encuentro a solas con } \\
\text { un visitante, que se autoriza a los presos' } \\
(D L E, \text { s. v. vis })\end{array}$ \\
\hline
\end{tabular}




\section{duplicación de la voz \\ arcaica vis ('Visage', $D E F$, LRDHLF)}

TABLA 1. Corpus de galicismos como préstamos fraseológicos presentes en locuciones españolas. Se observa: a) la voz idiomática que supone una palabra fósil; b) La etimología de la voz tratada, procedente de diccionarios con información etimológica (DLE) o etimológicos propiamente dichos (DCECH); c) La locución en la que se inserta la palabra idiomática, el tipo de locución que constituye y el significado de esta, según el DLE o el DEA, además de las marcaciones de uso (entre corchetes). Abreviaturas: adj. y adv. ([locución] adjetiva y adverbial), coloq. (coloquial), desus. (desusado/-a), loc. adj. (locución adjetiva), loc. adv. (locución adverbial), loc. policat. (locución policategorial), loc. verb. (locución verbal), s. $v$. (sub voce)

Como se puede comprobar, las once locuciones suponen un conjunto heterogéneo, ya que conforman hasta cinco tipos distintos de construcciones locucionales, que se distribuyen de la siguiente manera: cuatro locuciones adverbiales (al estricote, a gogó, de \{rondón/ rendón\} y vis a vis), cuatro adjetivas (de bote en bote, al gratín, de pitiminí y a la virulê), una verbal (entrar de rondón [alguien]), una sustantiva (vis a vis) y una policategorial o polifuncional $^{34}$ (a lo \{garsón/garçon/garçonne $\}$ ), ya que tiene la capacidad de funcionar como adjetiva y como adverbial.

\section{ANÁLISIS DEL CORPUS: PRINCIPALES CARACT'ERÍSTICAS DE LOS GALICISMOS COMO PRÉSTAMOS FRASEOLÓGICOS}

En el presente apartado realizaremos un análisis léxico-morfológico, partiendo de los planteamientos fraseológicos de Ruiz Gurillo (2001, pp. 52-53 y García-Page Sánchez (2008, pp. 352-387), mediante el cual examinaremos la configuración formal con la que han quedado fijadas las nueve piezas léxicas idiomáticas tomadas del francés insertas en las once locuciones en español que hemos inventariado. Comentaremos brevemente los aspectos adaptativos o conservadores que han influido en su proceso de adquisición como préstamos, poniendo especial interés en las adaptaciones o mantenimientos gráficos, fonológicos y morfológicos que han experimentado estas nueve voces idiomáticas. Seguimos para ello las directrices de estudio de las adquisiciones léxicas planteadas en las monografías de Gómez Capuz (2005) y Giménez Folqués (2012) y en las siguientes obras académicas: el Diccionario panhispánico de dudas (DPD, 2005), la Nueva gramática de la lengua española (NGLE, 2009) y la Ortografía de la lengua española (OLE, 2010).

\footnotetext{
${ }^{34}$ Cfr. Castillo Carballo (2000); García-Page Sánchez (2008, p. 119).
} 
Puede comprobarse que los galicismos léxicos que se han incorporado como palabras idiomáticas insertas en locuciones españolas han experimentado unos procesos de adaptación muy concretos, llegando a transferirse como préstamos adaptados (esto es, como voces que se han acomodado a los patrones fonológicos, silábicos, prosódicos, ortográficos y morfológicos característicos de la lengua meta o receptora, en este caso, el español ${ }^{35}$; cfr. OLE \ VI, 1; Gómez Capuz, 2005, pp. $14-$ 15), aunque algunos también conservan ciertos rasgos no acomodativos a la lengua meta que delatarían su procedencia foránea como piezas léxicas (es decir, como extranjerismos crudos o préstamos que manifiestan mayor resistencia a su acomodación en la lengua receptora, por lo que conservan, en mayor o menor medida, la grafía y pronunciación originarias; cfr. OLE 』 VI, 1; Gómez Capuz, 2005, pp. 1415; Casado Velarde, 2015, p. 125).

5.1. Respecto a los procedimientos de asimilación que estos galicismos han experimentado para integrarse como préstamos adaptados en el léxico español, podemos destacar los siguientes:

5.1.1. En primer lugar, se observan determinadas asimilaciones puramente fónicas, sin repercusiones gráficas, como:

5.1.1.1. La pérdida de la naturaleza uvular originaria de la /R/ francesa (Fagyal, Kibbee et al, 2006, p. 46) para adaptarse en español, bien como vibrante simple (/r/) en estricote $(<*$ estricot), gratín (< gratin), virulé (< bas roulè) y el set de variantes garsón/garçon/garçonne (< garçon) (en clúster consonántico en garsón/garçon/garçonne, estricote y gratín, o en posición intervocálica en virulê), bien como vibrante múltiple $(/ \overline{\mathrm{r}} /)$ en las variantes fónico-gráficas rondón/ rendón (< randon) (en este caso, por presentarse dicho fonema en inicial de palabra).

5.1.1.2. La conversión de la fricativa labiodental sonora (/v/) (Yllera Fernández, 1991, p. 242) en la oclusiva bilabial sonora (/b/) - o en su alófono fricativo / $\mathrm{b} /$ - en vis a vis

35 Hasta el punto de que pueda darse la posibilidad de que no exista en la conciencia lingüística del hablante el carácter de préstamo de estos (cfr. OLE \& VI, 1; Casado Velarde, 2015, p. 125; Moreno Cabrera, 2016, pp. 85-86). 
(/bi.sa.bis/). Supone un hecho de adaptación puramente fonológico, ya que en español se mantiene la grafía $v$ - originaria.

5.1.2. También presentan algunas adaptaciones de carácter estrictamente gráfico, sin repercusiones fónicas, de entre las que destacamos las siguientes:

5.1.2.1. Se observa la colocación de la tilde según las normas de acentuación en español de las palabras oxítonas (OLE \ II 3.4.1.2.1) en las voces originarias francesas polisilábicas que no han experimentado paragoge vocálica, esto es, en gratín (< gratin), rondón/ rendón (< randon) y la variante garsón (< garçon), o en las terminadas en vocal gogó $(<$ gogo $)$ y pitiminí $(<$ petit + menu $)$. A la inversa, se ha eliminado el acento grave originario francés de la preposición à en el caso de los calcos fraseológicos (Maíllo Salgado, 1983, pp. $339-340)^{36}$ a gogó $(<\underline{a}$ gogo) y vis a vis $(<$ vis- $\underline{a}-v i s)$, mientras que se ha mantenido, por las normas generales de acentuación de las voces agudas en español, la tilde sobre la vocal final originaria en virulé $(<$ bas roulêe).

5.1.2.2. Se han producido dos pérdidas de grafemas originarios destacables, ocurridas en las dos voces originadas mediante coalescencia o fusión gráfica de lemas franceses: por un lado, la eliminación de la grafía -s- en posición medial en virulé ( $<$ bas roulè), y por otro, la pérdida de la grafía - $t$ - en posición medial en pitimini $(<$ petit + menu $)$. Como puede observarse, ambas grafías se eliminan cuando pasan a ocupar posición intermedia, al perder su condición final en la primera base léxica de sus respectivos compuestos. Además, estas grafías no se correspondían con ninguna realización fonética en la lengua de origen.

5.1.2.3. Otra adaptación gráfica es la adopción de la grafía -s- para la ce cedilla $\left(-c_{-}-\right)$en la variante garsón (< garçon). La supresión de la grafía -ç- tuvo lugar en 1726 con la publicación del primer tomo de Autoridades, el primer diccionario académico (Ariza Viguera, 1998, p. 11), con la finalidad de reformar la ortografía y aportar coherencia al

36 O «incorporaciones fraseológicas» (Lapesa Melgar, 1981, p. 155), esto es, trasvase de material fraseológico de una lengua foránea al español mediante la incorporación o traducción, más o menos literal, como síntoma de intercambio cultural. Nótese que los componentes léxicos de sentido gramatical o «categorías vacías» (Bosque Muñoz, 2007, p. 30) (básicamente, preposiciones y determinantes artículos) coinciden formalmente con sus homónimos equivalentes en la lengua meta, de manera que estos elementos pueden sentirse como nativos, aislando el núcleo locucional inserto en una estructura

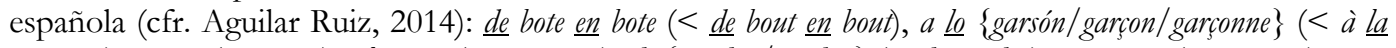
garconne), a gogó $(<\underline{a}$ gogo), al gratín $(<$ au gratin), de $\{$ rondón/rendón $\}(<$ de randon) y vis a vis $(<$ vis-à-vis). 
sistema ortográfico español (García de la Concha, 2014, p. 59). Ha de notarse, sin embargo, que en las otras dos variantes gráficas que presenta esta misma voz se ha mantenido la grafía con - ç- originaria, como extranjerismo crudo: a lo garçon (< garçon) y a lo garçonne (< garçonne).

5.1.2.4. La grafía $v$ - en el español virulé ha sustituido la grafía $b$ - originaria francesa ( $\underline{b} a s$ roulê), sin consecuencias fonológicas en la lengua receptora, al representar ambas grafías en español la oclusiva bilabial sonora (o su alófono aproximante, por su posición intervocálica dentro de su construcción locucional, a la virulể.

5.1.2.5. Puede apreciarse, además, la sustitución gráfica del fonema vocálico cerrado posterior /u/, representado por el dígrafo originario -ou- (como suele ser usual; cfr. Yllera Fernández, 1991, p. 151), por la grafía - $u$ - en español, en virulé (< bas roulè). Esta grafía resulta la transcripción usual en español (OLE \VI 3a; Giménez Folqués, 2012, p. 47$)^{37}$.

5.1.2.6. Una última adaptación gráfica observable, al suponer la locución vis a vis un calco fraseológico de la estructura francesa vis-à-vis (según la información etimológica del DLE, s. $v \cdot v i s^{2}$ ), sería la eliminación de los guiones de la estructura locucional originaria (vis-à-vis $>$ vis a vis).

5.1.3. Respecto a las asimilaciones fónico-gráficas (ya que un cambio fónico comporta un cambio gráfico; cfr. García-Page Sánchez, 2008, p. 227), se pueden rastrear las siguientes:

5.1.3.1. Paragoge vocálica, o desarrollo de una vocal final de apoyo (Lausberg, 1984, p. 27; Campbell, 1999, p. 35), en bote $(<$ bout) y estricote $(<*$ estricot $)$, recurso normalmente aplicado a galicismos y anglicismos (Gómez Capuz, 2005, p. 18). Con ello se intentaría evitar un "final consonántico duro" (Lapesa Melgar, 1981, p. 410) como resulta una consonante - $t$ en posición final de palabra, anómala en español (Gómez Capuz, 2005, p. 18).

5.1.3.2. En su trasvase al español, algunas voces francesas han cerrado las vocales originarias /a/ y / / / (gráficamente, $-a-$ y $-e$-) en la vocal anterior cerrada /i/

\footnotetext{
37 Como los casos de glamur $(<$ glamour $)$, limusina $(<$ limousine) o suvvenir $(<$ souvenir) (Giménez Folqués, 2012, p. 47).
} 
(gráficamente, $-i-)$, en los casos de virulé $(<$ bas + roulè) y pitiminini $(<$ petit + menu $)$. Ha sucedido, como se puede observar, en los dos casos en los que la voz diacrítica española se ha formado mediante la fusión gráfica de dos bases originarias francesas que constituían sílaba tónica. En sus resultados fusionados adaptados en español han perdido la tonicidad: la - $a$ - tónica de bas ha perdido su tonicidad en la adaptación soldada virulé, mientras que la -i- tónica de petit ha desplazado igualmente su tonicidad a la última sílaba en pitiminí. Por el contrario, la -e- cerrada a -i-píti (petit) y -mennu (-minni) de pitiminí no cumple esta condición de tonicidad originaria.

5.1.3.3. Se puede observar también el cierre de la vocal anterior cerrada labializada /y/ en posición final de la voz francesa menu (/məny/) (representada con la grafía - $u$, que es la más frecuente para este fonema; cfr. Yllera Fernández, 1991, p. 150). El fonema ha perdido su carácter labializado y se representa en español como una cerrada anterior (/i/), con la grafía -i, en -miní (pitiminî).

5.1.3.4. La única abertura de timbre observable en una vocal originaria francesa ha sido la abertura en /o/ de la /u/ originaria, gráficamente -ou-, en bote $(<$ bout $)$. Si bien esta no suele ser la transcripción usual de la pronunciación y grafía francesa del dígrafo -ou(OLE 』 VI 3a), el timbre vocálico /o/ se deba quizá por analogía con su voz homónima en español bote ${ }^{38}$.

5.1.3.5. Una observación fónico-gráfica reseñable tiene que ver con la posición de la sílaba tónica con la que han entrado en castellano las piezas léxicas aquí estudiadas. Del total de nueve, seis de ellas (garsón/garçon/garçonne, gogó, gratín, pitiminí, rondón/rendón y virule) se han incorporado como voces oxítonas, que al terminar en consonante $-n$ o en vocal han incorporado un acento gráfico de acuerdo con la acentuación de las voces agudas en español (OLE \II 3.4.1.2.1). Las tres únicas voces que no se han incorporado como oxítonas son la monosilábica vis y las que han experimentado paragoge vocálica (bote y estricote, ambas paroxítonas). Esta tendencia a la configuración como piezas léxicas oxítonas de los préstamos fraseológicos originarios del francés se

\footnotetext{
38 'Salto que da una pelota u otro cuerpo elástico que sale despedido al chocar contra una superficie dura' (DLE, s. v. bote $)$; 'Embarcación pequeña de remo, sin cubierta y cruzada de tablones que sirven de asiento' (DLE, s. v. bote').
} 
observa como relevante si se compara con la disposición acentual dispar de otras voces idiomáticas adquiridas como préstamos, tales como los latinismos ${ }^{39}$, catalanismos ${ }^{40}$, arabismos $^{41} \mathrm{o}$ italianismos ${ }^{42}$, por ejemplo.

5.1.4. Estos galicismos fraseológicos presentan, además, determinadas adaptaciones morfológicas en la lengua meta (Gómez Capuz, 2005, pp. 21 y ss.). En efecto, de los nueve préstamos de origen francés que en español se manifiestan como palabras diacríticas, cuatro voces (estricote, gratín, virulé y las variantes garsón/garçon/garçonne) evidencian en su estructura fija locucional una marca gramatical de género, explícito mediante un determinante artículo definido para las cuatro (al estricote, al gratín, a la virulé

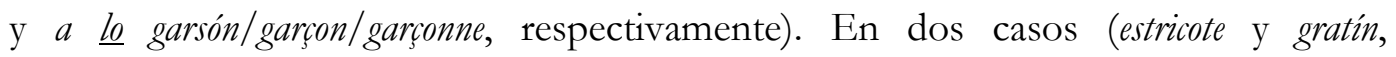
provenientes de *estricot y de la estructura au gratin) la adaptación se ha realizado en género masculino, aunque el resultado en español ha amalgamado el artículo masculino (el) con la preposición $a(a+\text { el estricote }>\text { al estricote; } a+\text { el gratín }>\text { al gratín })^{43}$. En un tercer caso (a la virulé) la adaptación ha tenido lugar en femenino, probablemente mediante la omisión del sustantivo media que parece haber originado, según el DLE (s. v. virulè) y el DCECH (s.v. bajo), la locución en español ([media] a la virulé < [Ø] bas roulè), tomando, como observa Gómez Capuz (2005, p. 22), el género gramatical del

${ }^{39}$ Las voces idiomáticas ave, fas y nefas, oremus, pópulo, proviso y quisque, presentes en las locuciones ave maría (purísima) ('1. Denota asombro o extrañeza. 2. U. como saludo al llamar a la puerta o entrar en una casa', DLE, s. v. ave), por fas o por nefas ('Justa o injustamente', DLE, s. v. fas), perder el oremus [alguien] ('Dicho de una persona: Perder el juicio o la cordura', DLE, s. v. oremus), hacer una de pópulo bárbaro [alguien] ('Tomar una resolución violenta o desatinada, sin reparar en inconvenientes', DLE, s. v. pópulo), al proviso ('Al instante', DLE, s. v. proviso) y $\{$ todo/cada $\{$ quisque/-i\} ('Cada cual, o cualquier persona', DLE, s. v. quisque). ${ }^{40}$ Corda, derrería, detall y granel, presentes en las locuciones estar a la corda [alguien/algo] ('Mar. Capear', DLE, s. v. corda), a la derrería ('A la postre, al fin o al cabo', DLE, s. v. derrería), al detall ('Al por menor', DLE, s. v. detall) y a granel ('1. Dicho de cosas menudas, como trigo, centeno, etc.: Sin orden, número ni medida. 2. Dicho de un género: Sin envase, sin empaquetar. 3. De montón, en abundancia', DLE, s. v. graneð) (Aguilar Ruiz, en prensa).

41 Balde, guájete y (h)erre, presentes en las locuciones de balde ('1. Gratuitamente, sin coste alguno. 2. En vano. 3. Sin motivo, sin causa', DLE, s. v. balde), en balde ('En vano', DLE, s. v. balde), estar de balde [alguien] ('Estar de más, estar ocioso', DLE, s. v. balde), guájete por guájete ('Tanto por tanto, una cosa por otra', DLE, s. v. guájete), (b)erre que (h)erre ('Porfiadamente, tercamente', DLE, s. v. erre') y estar (b)erre [alguien] ('Mantenerse firme en un propósito', DLE, s. v. erre²).

42 Berlina, dente y ufo, presentes en las locuciones en berlina ('En ridículo. Poner, quedar en berlina', DLE, s. $v$. berlina'), al dente ('Dicho de los tallarines, los macarrones, etc.: Cocidos de manera que conserven una cierta consistencia', DLE, s. v. dente) y a ufo ('De gorra, de mogollón, sin ser convidado ni llamado', DLE, s. $v$. $u f o$ ).

${ }^{43}$ En au gratin, en concreto, la forma au es la forma contracta de la preposición à más la forma masculina del artículo le (Wilmet, 1997, p. 136). 
equivalente o parasinónimo de la lengua meta (en este caso, el sustantivo media). No obstante, la aparición de este determinante artículo definido en femenino supone también, como observa Ruiz Gurillo (1998, pp. 22-24), un procedimiento de fijación locucional para expresar la manera o resultado de la acción verbal, contemplable como una anomalía estructural, "sin que exista [en la estructura locucional] una verdadera razón de concordancia o de otro tipo para ello” (Ruiz Gurillo, 1998, p. 22). El cuarto y último caso de adaptación morfológica manifiesta en una fijación locucional lo constituye la aparición de un artículo definido neutro lo en a lo \{garsón/garcon/garconne\}, señalado también como un procedimiento recurrente para originar estructuras fijas locucionales, al igual que el artículo femenino $l a$, con el que alterna en ocasiones (cfr. Mariner Bigorra, 1968, pp. 1301-1302).

El total de los distintos tipos de adaptaciones que han experimentado este tipo de préstamos fraseológicos de origen francés se ofrece resumido en la tabla 2.

\begin{tabular}{|c|c|}
\hline \multicolumn{2}{|c|}{ ADAPTACIONES FONOLÓGICAS } \\
\hline $\begin{array}{l}\text { Pérdida de la naturaleza uvular de la } \\
\qquad / \mathbf{R} /\end{array}$ & $\begin{array}{c}\text { estricote } \\
\text { garsón/garçon/garconne } \\
\text { gratín } \\
\text { rondón/ rendón } \\
\text { virulé }\end{array}$ \\
\hline $\begin{array}{c}\text { Fricativa labiodental sonora }(/ \mathrm{v} /)> \\
\text { oclusiva/aproximante bilabial sonora } \\
(/ \mathrm{b} / \mathrm{o} / \mathbf{b} /)\end{array}$ & $\underline{v} i s$ a $\underline{v} i s(<\underline{v} i s-\grave{a}-\underline{v} i s)$ \\
\hline
\end{tabular}




\section{ADAPTACIONES GRÁFICAS}

\begin{tabular}{|c|c|}
\hline Tilde & $\begin{array}{l}\text { variante garsón } \\
\text { gogó } \\
\text { gratín } \\
\text { pitiminí } \\
\text { rondón/rendón } \\
\text { virulé }\end{array}$ \\
\hline $\begin{array}{l}\text { Pérdida de tilde en la preposición } a ̀ \text { : } a ̀ \\
>>a\end{array}$ & $\begin{array}{l}\text { vis a vis }(<\text { vis-à-vis }) \\
\text { a gogó }(<\grave{a} \text { gogo })\end{array}$ \\
\hline Grafía $-c->-s-$ & variante garsón $(<$ garçon $)$ \\
\hline Pérdida de $-s$ - en posición medial & virulé $(<$ bas roulé) \\
\hline Pérdida de $-t$ - en posición medial & pitimini $(<$ petit + menu $)$ \\
\hline Grafía -ou- > -u- & virulé $(<$ bas roulé) \\
\hline $\begin{array}{l}\text { Oclusiva bilabial sonora }(/ \mathbf{b} /) \text { en } \\
\text { aproximante bilabial sonora }(/ \mathbf{b} /) \text { : } \\
\qquad(/ \mathbf{b} /)>(/ \mathbf{b} /)\end{array}$ & [la] virulé $(<\underline{\text { bas roulè })}$ \\
\hline Eliminación de los guiones originarios & vis a vis $(<v i s-\grave{a}-v i s)$ \\
\hline
\end{tabular}

\section{ADAPTACIONES FÓNICO-GRÁFICAS}

\begin{tabular}{|c|c|}
\hline Paragoge & $\begin{array}{c}\text { bote }(<\text { bout }) \\
\text { estricote }(<\text { estricot })\end{array}$ \\
\hline Abertura /u/ (-ou-) $>/ \mathrm{o} /(-o-)$ & bote $(<$ bout $)$ \\
\hline Cierre /o/ > /i/ & pịtimini $(</$ pəti $/+/$ məny/) \\
\hline $\begin{array}{l}\text { Cierre de } / \tilde{\varepsilon} / \text { abierta nasalizada en } / \mathrm{i} / \\
\qquad(/ \tilde{\varepsilon} />/ \mathrm{i} /)\end{array}$ & $\operatorname{gratin}(</$ gRat $\tilde{\varepsilon} /)$ \\
\hline $\begin{array}{l}\text { Cierre de la vocal abierta central } \\
\text { originaria / a / a cerrada anterior /i/ }\end{array}$ & virulé $(<$ bas roulè) \\
\hline $\begin{array}{l}\text { Cierre del carácter redondeado de la } \\
\quad \text { vocal } / \mathrm{y} /: / \mathrm{y} /(-u-)>/ \mathrm{i} /\end{array}$ & pitiminú $(</$ pəti $/+/$ məny $/)$ \\
\hline $\begin{array}{c}\text { Cierre de /a/ en las vocales medias } \\
\text { /e/ y /o/ }\end{array}$ & rondón/ rendón $(<$ randon $)$ \\
\hline
\end{tabular}




\section{ADAPTACIONES MORFOLÓGICAS}

\begin{tabular}{|c|c|}
\hline $\begin{array}{l}\text { Mediante determinante artículo } \\
\text { (masculino singular) }\end{array}$ & $\begin{array}{l}\text { el estricote } \\
\text { el gratin }\end{array}$ \\
\hline $\begin{array}{l}\text { Mediante determinante artículo } \\
\text { (femenino singular) }\end{array}$ & la virulé \\
\hline $\begin{array}{c}\text { Mediante determinante artículo } \\
\text { (neutro) }\end{array}$ & lo garsón/garçon/garçonne \\
\hline
\end{tabular}

TABLA 2. Adaptaciones observadas en los galicismos fraseológicos

5.2. Por otro lado, también pueden observarse determinados mantenimientos gráficos que delatarían la procedencia foránea de este léxico (OLE \VI, 1; Casado Velarde, 2015, p. 125; Moreno Cabrera, 2016, pp. 85-86). Así:

5.2.1. No se ha tildado, según las normas generales de acentuación de las voces oxítonas en español (OLE \II 3.4.1.2.1), la variante garçon (< garçon).

5.2.2. Se ha mantenido la grafía -ç- (eliminada en español, como se ha comentado, en 1726, en el prólogo de Autoridades) en las variantes garçon y garçonne (a lo $\{$ garçon/garçonne $\}$ ), frente a la variante plenamente adaptada garsón (a lo garsón).

5.2.3. Se observa la geminación de las nasales - nn- en la variante garçonne.

5.2.4 Podría apuntarse, por último, la no pronunciación de la -e final en garçonne, fiel a la pronunciación original.

Como se puede observar en la tabla 3, todas las características anteriores se presentan en las variantes garçon y garçonne, y suponen los mantenimientos gráficos más llamativos, ya que evidencian ambas variantes como extranjerismos crudos, no adaptados $(D P D$, pp. XIX-XX; OLE \VI, 1).

\section{MANTENIMIENTOS}

\begin{tabular}{|c|c|}
\hline $\begin{array}{l}\text { Ausencia de acento gráfico } \\
\text { acorde con la acentuación de las } \\
\text { oxítonas }\end{array}$ & variante $\operatorname{garçon} n(<$ garçon $)$ \\
\hline Grafía -ç- & $\begin{array}{c}\text { variante garcon }(<\text { garcon }) \\
\text { variante garçonne }(<\text { garconne })\end{array}$ \\
\hline Geminación de nasales -nn- & variante garçonne $(<$ garçonne $)$ \\
\hline No pronunciación de la $-e$ final & variante garçonne (< garçonne $)$ \\
\hline
\end{tabular}




\section{CONCLUSIONES}

En el presente artículo se ha analizado la configuración formal con la que han quedado fijados en su estructura locucional los nueve galicismos fraseológicos con los que contamos en nuestro inventario de palabras idiomáticas. En estas nueve piezas léxicas diacríticas pueden verse reflejados los dos procedimientos extremos que pueden recibir las voces incorporadas en calidad de préstamos léxicos: en primer lugar, la total adaptación, según la pronunciación y grafías originales, sin tener en cuenta su grafía y sin hallar mayores problemas gráficos, fonológicos y morfológicos en español, necesitando un mínimo de adaptación, que resulta la tendencia mayoritaria. En segundo lugar, se puede observar también la opción opuesta a la anterior, que consiste en su aceptación en crudo, como extranjerismos sin adaptar, en las variantes garçon y garçonne. Estos últimos presentan, por un lado, grafías que delatan su condición de xenismos, como la ce cedilla (-c-) en las variantes garçon y garçonne y, por otro, encuentros consonánticos anómalos, como la doble consonante nasal alveolar (-nn-) en la variante garçonne. Los procedimientos de adaptación han sido muy variados, ya que se puede observar distintos tipos de adaptaciones fónico-gráficas (paragoges, cambios vocálicos, desnasalizaciones, etc.), adaptaciones puramente fonológicas, sin repercusiones gráficas (como la pérdida de la uvularidad de la /R/ originaria francesa), acomodaciones puramente gráficas, sin consecuencias fonológicas (adición de tilde, adaptaciones de grafías, eliminación de guiones originarios, etc.) y adaptaciones morfológicas (mediante la adición de un determinante artículo en la fijación formal locucional).

En nuestro corpus global de palabras idiomáticas presentes en locuciones españolas recopiladas en el $D L E$ y el $D E A$, contamos con un total de treinta y siete préstamos fraseológicos, procedentes de hasta diez lenguas distintas. Según el estado actual de nuestra investigación, se puede afirmar que las palabras idiomáticas procedentes de la lengua francesa suponen los préstamos más numerosos en la masa fraseológica en español en lo que se refiere a voces diacríticas desde una concepción estrecha, pues, efectivamente, los nueve galicismos fraseológicos aquí estudiados convierten el francés en la lengua que más préstamos idiomáticos ha aportado al español (con las nueve 
piezas léxicas presentes en este estudio), seguido de la lengua latina (con siete casos, antes mencionados en la nota a pie núm. 39) y de la catalana (con los cuatro casos comentados supra, en la nota 40). Otras lenguas se reparten la representación con hasta tres préstamos, como los procedentes del árabe y del italiano (comentados antes, en las notas 41 y 42) o del inglés (Aguilar Ruiz, 2020), entre otros orígenes.

Podríamos aventurar que el eje diacrónico puede suponer un factor clave en el grado de adaptación de estos préstamos fraseológicos, ya que, extrapolando nuestras observaciones al tratamiento de los préstamos del léxico general (siguiendo a Gómez Capuz, 2005, pp. 18 y ss. y la OLE \VI 1), en las voces más antiguas suele optarse por la adaptación casi total (hasta el punto de que no se les podría intuir un origen foráneo), sobre todo bote $(<$ bout $)$ y estricote $(<*$ estricot), que han experimentado paragoge vocálica para evitar un "final consonántico duro" (Lapesa Melgar, 1981, p. 410), mientras que las incorporaciones más recientes (como las variantes garçon y garçonne) suelen presentarse más reacias a la adaptación, quedando como extranjerismos crudos.

Hemos centrado exclusivamente este estudio, no obstante, en la configuración formal de estos nueve galicismos idiomáticos en español, pero el presente análisis supone tan solo una primera aproximación a estas voces anómalas actualizables únicamente dentro de locuciones en español. Quedan abiertas aún diversas líneas de investigación desde el punto de vista fraseológico, como serían, por ejemplo, el análisis detallado de la configuración sintagmática y funcional que manifiestan las locuciones aquí reseñadas, o la indagación sobre sus comportamientos semánticos o pragmáticos. 


\section{BIBLIOGRAFÍA}

Aguilar Ruiz, M. J. (2010). Las palabras diacríticas en español: notas para su estudio e intento de clasificación. Interlingüistica XXI. Actuales líneas de investigación en el panorama internacional de los jóvenes lingüistas, pp. 367-377.

Aguilar Ruiz, M. J. (2011). Vilo, repente y santiamén: los fósiles fraseológicos como palabras diacríticas en la fraseología española. En E. Carmona Yanes y S. del Rey Quesada (Eds.). Id est, loquendi peritia. Aportaciones a la Lingüística Diacrónica de los Jóvenes Investigadores de Historiografía e Historia de la Lengua Española. Sevilla: Universidad de Sevilla, pp. 87-96. (CD-ROM). [En línea] http://institucional.us.es/idestloquendi/ [18/05/2020].

Aguilar Ruiz, M. J. (2012). "Neologismos fraseológicos" como palabras diacríticas en las locuciones en

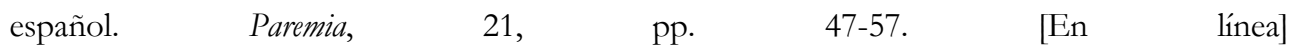
http://cvc.cervantes.es/Lengua/paremia/pdf/021/005 aguilar.pdf [18/05/2020].

Aguilar Ruiz, M. J. (2014). Locuciones españolas con latinismos como palabras diacríticas. En V. Álvarez Vives, E. Díez del Corral Eleta y N. Reynaud Oudot (Eds). 2014. Dándole cuerda al reloj. Ampliando perspectivas en lingüistica histórica de la lengua española. Valencia: Tirant Humanidades, pp. 267-284.

Aguilar Ruiz, M. J. (2019). Palabras idiomáticas como “pistas perdidas" en la última edición del diccionario académico (DLE, 2014). En M. Quilis Merín y J. Sanmartín Sáez (Eds.). Historia e historiografía de los diccionarios del español. Anejo núm. 11 de Normas. Revista de estudios lingüisticos hispánicos, $\quad$ pp. 323-328. [En línea] https://www.uv.es/normas/2019/anejos/historia historiografia.pdf [18/05/2020].

Aguilar Ruiz, M. J. (2020). "Por si las flais", “ni flowers” y “en off”: la configuración formal de los anglicismos léxicos como palabras idiomáticas en locuciones en español. Tonos Digital, 39(II), pp. 1-21. [En línea] http://www.tonosdigital.com/ojs/index.php/tonos/article/view/2550 [19/10/2020].

Aguilar Ruiz, M. J. (en prensa). Configuración formal de cuatro catalanismos léxicos como palabras idiomáticas en locuciones en español. Actas del XXXIV Congreso Internacional de la Asociación de Jóvenes Lingüistas, Universitat de València, Valencia.

Álvarez de Miranda de la Gándara, P. (2009). Neología y pérdida léxica. En E. de Miguel Aparicio (Ed.). Panorama de la lexicología. Barcelona: Ariel, pp. 133-158.

Álvarez de Miranda de la Gándara, P. (2013 [2004]). El léxico español, desde el siglo XVIII hasta hoy. En R. Cano Aguilar (Coord.). op. cit., pp. 1037-1064.

Ariza Viguera, M. (1998). El comentario filológico de textos. Madrid: Arco Libros.

Battaner Arias, P. y C. López Ferrero (2019): Introducción al léxico, componente transversal de la lengua. Madrid: Cátedra, pp. 89-129.

Boer, C. de 1954 [19471). Syntaxe dy français moderne. Leiden: Universitaire Pers Leiden.

Bosque Muñoz, I. (2007 [1990]). Las categorías gramaticales. Madrid: Síntesis.

Campbell, L. (1999): Historical linguistics: an introduction. MIT: Cambridge, Massachusetts.

Cano Aguilar, R. (Coord.) (2013 [2004]). Historia de la lengua española. Barcelona: Ariel.

Cano Aguilar, R. (2015 [1988]). El español a través de los tiempos [8. a edición]. Madrid: Arco Libros. 
Casado Velarde, M. (2015). La innovación léxica en el español actual. Madrid: Síntesis.

Castillo Carballo, M. ${ }^{a}$ A. (2000). Nuevo tipo de locuciones: las adjetivo-adverbiales. En A. Pamies Bertrán y J. de D. Luque Durán (Coords.). Trabajos de lexicología y fraseología contrastivas. Granada: Método, pp. 137-144.

Castillo Carballo, M. ${ }^{a}$ A. (2003). La macroestructura del diccionario. En A. M. ${ }^{a}$ Medina Guerra (Coord.). Lexicografía española. Barcelona: Ariel, pp. 79-101.

Clavería Nadal, G. (2013). Los caracteres de la lengua en el siglo XIII: el léxico. En R. Cano Aguilar (Coord.). op. cit., pp. 473-504.

Colón Doménech, G. (2002). Para la historia del léxico español (I) [Edición preparada por A. Soler y N. Mañé]. Madrid: Arco Libros.

Corpas Pastor, G. (1996). Manual de fraseología española. Madrid: Gredos.

Corriente Córdoba, F. (2013). El elemento árabe en la historia lingüística peninsular: actuación directa e indirecta. Los arabismos en los romances peninsulares (en especial, en castellano). En R. Cano Aguilar (Coord.). op. cit., pp. 185-206.

Coseriu, E. (1986 [1967]). Principios de semántica estructural. Madrid: Gredos.

DCECH = J. Coromines i Vigneaux y J. A. Pascual Rodríguez (1980-1992). Diccionario crítico etimológico castellano e hispánico. Madrid: Gredos.

DDFH = Buitrago Jiménez, A. (2007 [1995]). Diccionario de dichos y frases hechas. Madrid: Espasa Calpe.

DE $A=$ Seco Reymundo, M., O. Andrés Puente y G. Ramos González (2011). Diccionario del español actual (2. ${ }^{a}$ edición actualizada). Madrid: Aguilar.

DEF $=$ Picoche, J. (1991[1983]). Dictionnaire etymologique du français. Montreal: Le Robert.

DFDE $A$ = Seco Reymundo, M., O. Andrés Puente y G. Ramos González (2004). Diccionario fraseológico documentado del español actual. Madrid: Aguilar.

$D L E=$ Real Academia Española y Asociación de Academias de la Lengua Española (2014). Diccionario de la lengua española (23. ${ }^{\text {a }}$ edición). Madrid: Espasa.

$D P D=$ Real Academia Española y Asociación de Academias de la Lengua Española (2005). Diccionario panhispánico de dudas. Madrid: Santillana.

DRAE22 = Real Academia Española (2001). Diccionario de la lengua española (22. a edición). Madrid: Espasa Calpe.

DTLCCE = Sevilla Muñoz, J. y J. Cantera Ortiz de Urbina (2004). Diccionario temático de locuciones francesas con su correspondencia española. Madrid: Gredos.

DUE = Moliner, M. (2007[1967]): Diccionario de uso del español (3. ${ }^{a}$ edición). Madrid: Gredos [edición en CD-ROM, versión 3.0.].

Fagyal, Z., D. Kibbee y F. Jenkins (2006). French: A Linguistic Introduction. Cambridge: Cambridge University Press. https://doi.org/10.1017/CBO9780511791185

García de la Concha, V. (2014). La Real Academia Española. Vida e historia. Barcelona: Espasa. https://doi.org/10.6035/Humanitats.2005.19 
SECCIÓN: LEXICOLOGÍA

SOBRE LA CONFIGURACIÓN FORMAL DE GALICISMOS LÉXICOS COMO PALABRAS IDIOMÁTICAS EN

ESTRUCTURAS LOCUCIONALES EN ESPAÑOL

Manuel José Aguilar Ruiz

García-Page Sánchez, M. (1990). Léxico y sintaxis locucionales: algunas consideraciones sobre las palabras "idiomáticas". Estudios Humanísticos. Filología, 12: 279-290. https://doi.org/10.18002/ehf.v0i12.4052

García-Page Sánchez, M. (1991). Locuciones adverbiales con palabras “idiomáticas”. Revista Española de Lingüistica, 21(2): 211-264.

García-Page Sánchez, M. (2008). Introducción a la fraseología española. Estudio de las locuciones, Barcelona, Ánthropos.

Giménez Folqués, D. (2012). Los extranjerismos en el español académico del siglo XXI. Anexo núm. 3 de Normas. Revista de Estudios Lingüisticos Hispánicos. [En línea] https://www.uv.es/normas/2012/ANEJOS/Libro\%20Gimenez 2012.pdf [20/05/2020].

Gómez Capuz, J. (2005). La inmigración léxica. Madrid: Arco Libros.

Haensch, G. (1982). Aspectos prácticos en la elaboración de diccionarios. En G. Haensch, L. Wolf, S. Ettinger y R. Werner (Eds.) (1982. La lexicografía. De la lingüística teórica a la lexicografía práctica. Madrid: Gredos, pp. 395-534.

Lapesa Melgar, R. (1981 [1942]). Historia de la lengua española (novena edición, corregida y aumentada). Madrid: Gredos.

Lausberg, H. (1984 [1967]). Manual de retórica literaria. Madrid: Gredos.

Lorenzo Criado, E. (1996). Anglicismos hispánicos. Madrid: Gredos.

LPRLF = Rey, A., J. Rey-Debove y P. Robert (2004 [1967]). Le Petit Robert- Langue française. París: Dictionnaires Le Robert

LRDHLF = Rey, A. (dir.) (2000 [1992]). Le Robert. Dictionnaire historique de la langue française. París: Dictionnaires Le Robert.

Maíllo Salgado, F. (1983). Los arabismos del castellano en la Baja Edad Media (Consideraciones históricas y filológicas). Salamanca: Ediciones de la Universidad de Salamanca-Instituto Hispanoárabe de cultura.

Mariner Bigorra, S. (1968). El femenino de indeterminación. En A. Quilis Morales, R. Blanco Carril y M. Canterero (Eds.). Actas del XI Congreso Internacional de Lingüistica y Filología Románica. Madrid: CSIC, pp. 1297-1314.

Martí Contreras, J. (2003). Introducción a las unidades fraseológicas: las palabras diacríticas en los diccionarios españoles. Interlingü̈stica, 14: pp. 661-670. [En línea] http://dialnet.unirioja.es/servlet/articulo?codigo=918796 [20/10/2020].

Martí Contreras, J. (2005). "Ni fu ni fa" o del estudio de las palabras diacríticas dentro de las unidades fraseológicas españolas. En M. a del C. Cazorla Vivas, N. M. Contreras Izquierdo, M. Á. García Aranda y M. á. Moreno Moreno (Coords.). Estudios de historia de la lengua e historiografía lingüistica (Actas del III Congreso Nacional de la Asociación de Jóvenes investigadores de Historiografia e Historia de la Lengua Española). Madrid: AJIHLE, pp. 287-294.

Martínez López, J. A. (1997-1998). La palabra como unidad de significado: Algunas excepciones al respecto. Cauce: Revista de filología y su didáctica, 20-21, vol. 2 (Homenaje a Amado Alonso [19861996]), pp. 845-871. [En línea] http://cvc.cervantes.es/Literatura/cauce/pdf/cauce2021/cauce20-21 39.pdf [18/05/2020]. 
SECCIÓN: LEXICOLOGÍA

SOBRE LA CONFIGURACIÓN FORMAL DE GALICISMOS LÉXICOS COMO PALABRAS IDIOMÁTICAS EN ESTRUCTURAS LOCUCIONALES EN ESPAÑOL

Manuel José Aguilar Ruiz

Medina López, J. (1997). Lenguas en contacto. Madrid: Arco Libros.

Medina López, J. (1999). Historia de la lengua española I. Español medieval. Madrid: Arco Libros.

Moreno Cabrera, J. C. (2004). Introducción a la lingüistica. Enfoque tipológico y universalista. Madrid: Síntesis.

Moreno Cabrera, J. C. (2016). Multilingüismo y lenguas en contacto. Madrid: Síntesis.

NGLE = Real Academia Española y Asociación de Academias de la Lengua Española (2009). Nueva gramática de la lengua española. Madrid: Espasa.

$O L E=$ Real Academia Española y Asociación de Academias de la Lengua Española (2010). Ortografía de la lengua española. Madrid: Espasa.

Penny, R. (2014 [1993]). Gramática histórica del español [Traducción de J. I. Pérez Pascual y M.a E. Pérez Pascual]. Barcelona: Ariel.

Pico Graña, B. y D. Corbella Díaz (1987-1988). Galicismos en español medieval. Modificaciones de contenido en los sustantivos de clasema "persona". Revista de Filología de la Universidad de La Laguna, 6 y 7, pp. 367-394. [En línea] https://dialnet.unirioja.es/servlet/articulo?codigo=91684 [26/05/2020].

Posner, R. (1998 [1996]). Las lenguas romances [Traducción al español de S. Iglesias]. Madrid: Cátedra.

Pottier, B. (1967). Galicismos. En M. Alvar López et al. (Eds.). Enciclopedia de Lingüística Hispánica [tomo II: Elementos constitutivos y fuentes]. Madrid: CSIC, pp. 126-151.

Ruiz Gurillo, L. (1997. Aspectos de fraseología teórica española (Anejo XXIV de Cuadernos de Filología). Valencia: Universitat de València.

Ruiz Gurillo, L. (1998). La fraseología del español coloquial. Barcelona: Ariel.

Ruiz Gurillo, L. (2000). Cómo integrar la fraseología en los diccionarios monolingües. En G. Corpas Pastor (Ed.). Las lenguas de Europa: Estudios de fraseología, fraseografía y traducción. Granada: Comares, 261-274.

Ruiz Gurillo, L. (2001). Las locuciones en español actual. Madrid: Arco Libros.

Seco Reymundo, M. (1991 [1989]). La vida de las palabras. En M. Seco Reymundo (1991 [1989]). Gramática esencial del español. Introducción al estudio de la lengua [2. ${ }^{a}$ edición, revisada y aumentada]. Madrid: Espasa-Calpe, pp. 223-247.

Wilmet, M. (1997). Grammaire critique du Français. Louvain-la-Neuve: Ducolot Hachette.

Wotjak, B. (1998). Unidades fraseológicas en un diccionario de aprendizaje del alemán como lengua extranjera. En G. Wotjak (Ed.). Estudios de fraseología y fraseografía del español. Frankfurt y Madrid: Vervuert Iberoamericana, pp. 343-363. https://doi.org/10.31819/9783865278371-020

Yllera Fernández, M.a A. (1991). Fonética y fonología francesas. Madrid: UNED.

Zuluaga Ospina, A. (1980). Introducción al estudio de las expresiones fijas. Frankfurt y Berna: Peter D. Lang Verlag.

Zurita, M. ${ }^{a}$ E. (2008). Palabras diacríticas y anomalías estructurales. Comunicación en el XI Congreso de la Sociedad Argentina de Lingüística, Santa Fe, 9-12 de abril de 2008. 